\title{
OPTIMIZATION OF IMPACT VIBRATION ISOLATION
}

\author{
Davorka Šaravanja, Marko Grbešić \& Mario Dragičević
}
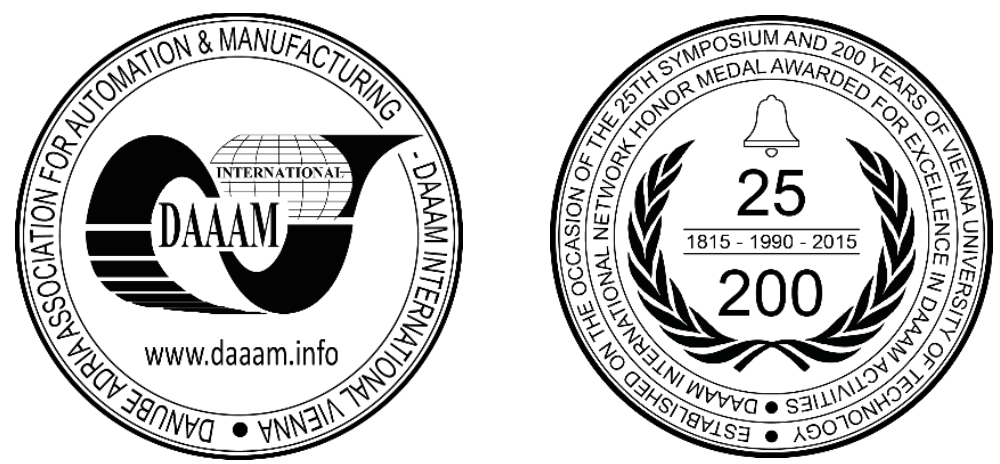

This Publication has to be referred as: Saravanja, D[avorka]; Grbesic, M[arko] \& Dragicevic, M[ario] (2016). Optimization of Impact Vibration Isolation, Proceedings of the 27th DAAAM International Symposium, pp.0044-0050, B. Katalinic (Ed.), Published by DAAAM International, ISBN 978-3-902734-08-2, ISSN 1726-9679, Vienna, Austria DOI: $10.2507 / 27$ th.daaam.proceedings.007

\begin{abstract}
Impact machines are designed to generate high dynamic forces with each impact hammer. Conventionally designed bases of these machines require relatively large reinforced concrete blocks to transfer the impact force to the ground. Size basic block is dependent on a loading force produced a hammer and the characteristics of the soil. The vibrations generated by blows of hammers also be transmitted to the ground. These vibrations can have large impact and consequences on equipment, employees and even to the building structure. Recently, large investments in research and development of new technologies vibration isolation for impact machinery using the steel coil springs and viscous fluid dampers. The old solutions of elastic foundations are required large inertial mass under the hammer. With constant research and development to come up with new solutions that provide direct support to the impact machines using springs, without using a inertial mass.
\end{abstract}

Keywords: impact machines; vibration isolation; hammer, isolator.

\section{Introduction}

In recent years, increasingly used vibration isolators with coil springs and elastic elements, because they showed better qualities compared to conventional anti-vibration stand, because they are designed to be low-level and they are very effective for low frequency vibrations. The combination of coil springs and elastic elements enables greater efficiency for higher frequency range making it even more effective in the control of vibration. [1]

Their quality to conventional anti-vibration pads in the specific surface that acts as a sound barrier and increases the effect of isolation at high frequencies, which are transmitted through the spring.

In today's conditions often exceed the levels permitted by environmental noise due to the impact of industrial plants or craft workshops. In addition to noise, heavy machinery used in industrial production generate very strong vibrations. The reasons may be different from non-quality spatial planning, housing industrial facilities and craft workshops, inappropriate places in the area (near residential buildings) or poor isolation. Overdrafts level can be several times higher than permitted, and in some cases the level of vibration cannot be reduced to the appropriate technical measurement frameworks.

Sound isolation plant using silencers is the core problem, but no less important is not reducing vibrations that create impact and very heavy machinery. As much as it takes care of the design, balancing and installation (assembly), it is inevitable that the work of these machines follows the emergence of cyclical vibration phenomena of varying intensity, which run the entire mass. The problem consists in the isolation of the machine from the substrate structure to prevent 
vibration can be transmitted. Therefore, between the machine and the structure of the substrate should be set element that absorbs vibration energy in its two alternative components (usually vertical). This element must be flexible in order to stop the direction of the forces, which means should be installed anti-vibration elements-insulators. Isolating element should be resistant to the weight of the machine, ie. should be chosen as a function of its weight and the natural frequency of vibration of the machine. [2]

This problem is particularly acute in the area located on the rocky soil that is subject to the transmission of vibrations to the environment of the installed plant of this type.

\section{Designing optimal procedure vibration isolation}

Technical methods for solving these problems are in the optimization process of vibration isolation on mechanical machines that generate unacceptable levels of vibration and which not only threaten the characteristics of the machine, but also affect the threat to equipment in their environment. The starting point for the selection of such an isolator to form an optimal relationship between quantities such as $\omega_{\mathrm{n}}$-natural frequency $(\mathrm{Hz})$; $\omega$-excitation frequency $(\mathrm{Hz})$; $\mathrm{T}$ transmissibility function $(\%)$ and the d-static deflection $(\mathrm{mm})$.

Thus, when designing the optimal procedure vibration isolation external excitation forces must follow the basic principles for calculating transfer functions, depending on the modification of the vibration characteristics (frequency, stiffness and damping coefficients).

The vibration isolation is a way of reducing the dynamic forces that are transmitted from the vibrating system to another system that should protect the construction or equipment nearby.

Thus, the isolation is a process in which isolator receives vibrational energy of the base system (in return use force on the system that is equal and opposite to vibrational excitation), ie. preventing vibration motion, and the energy it receives, gradually dissipates, so it is advisable and specific damping the isolation. Otherwise, the two resonances that occur in isolation, would have infinite value, and dampers isolators have just role up maximum resonance value.

Optimal vibration isolator with its frequency corresponds to a very short field frequency relationship, because only in this area allows a certain balance. Terms of designing optimal isolator, can be realized in several ways:

- Reducing the excitation force;

- The change of activity and the frequency of the excitation force;

- By changing the stiffness of the system in order to avoid adverse cases resonance;

- Based on the elastic energy absorbing the excitation forces and so prevent the passage of energy to the sensitive parts of the system;

- Proper selection of the machine which influences the acceptable dynamic response of a structure;

- Elimination of local vibration increasing rigidity of vibrating elements, which can be achieved by installing stiffeners.

In large impact machines with very high dynamic loads due to the rapid movement of workpieces or machine parts with very high requirements, improve vibration isolation can be achieved by adding additional mass in the system. Figure 1. shows the measured values obtained from the analysis of vibration system with and without isolators. [2]

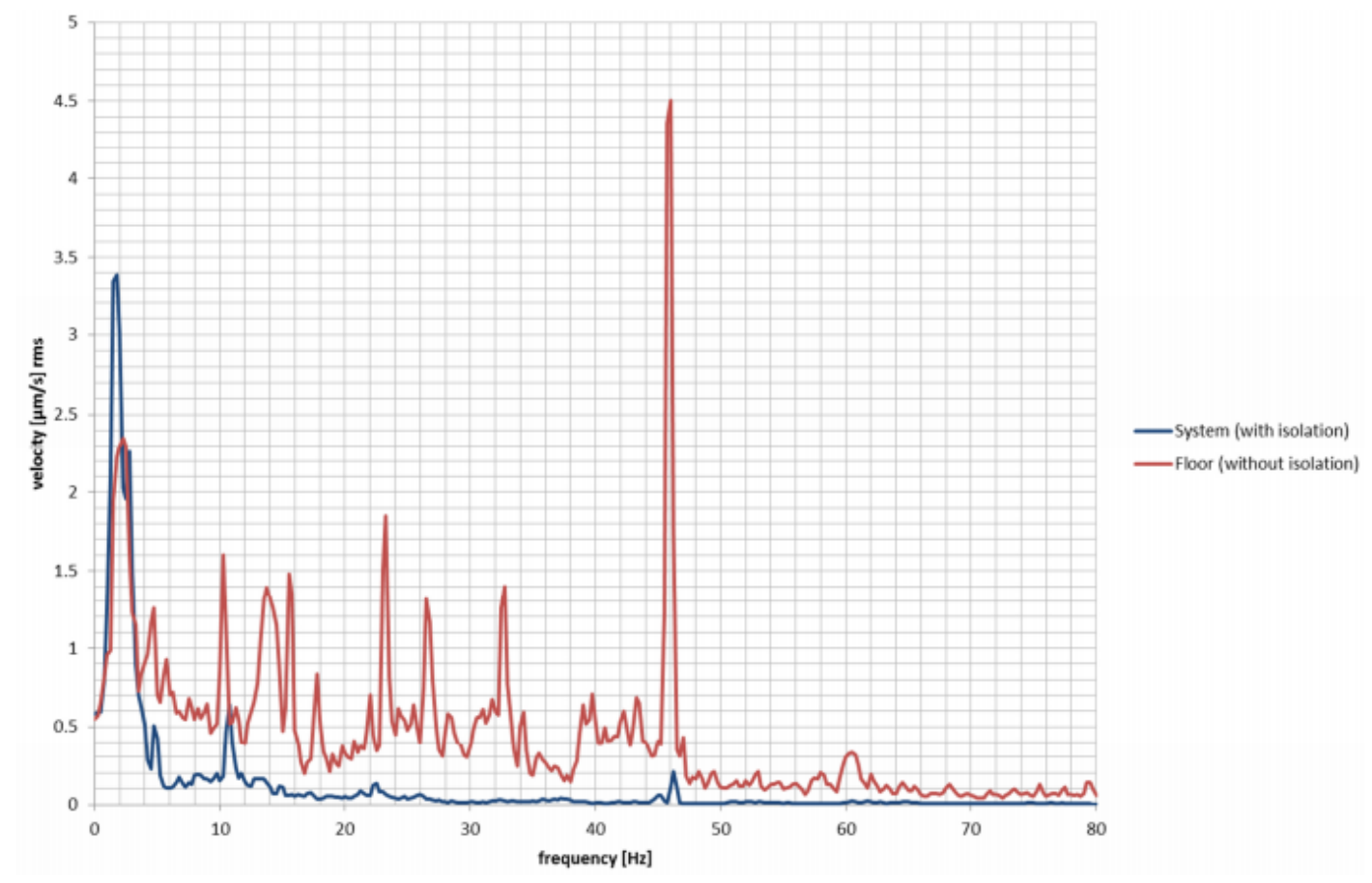

Fig. 1. Vibration analysis with and without vibration isolation 


\subsection{Vibration isolation heavy impact machines-impact hammers and forging machines}

When performing the isolation of heavy impact machines the same should be placed on vibrating isolators and thus isolate them from the dynamic communication aimed at these machines. In practice, there are so called single layered, double and sometimes a triple layer type of vibration isolation. In the single-type vibration isolating used different variations of suspension by vibration isolators on the structure that is to be isolated. Between the machine and the vibration isolators is usually by the relevant plates of certain characteristics customized design suspension (steel, aluminum or even steel-concrete). Today, optimization impact vibration isolators realized in the form of special supports, so they can be:

- Spring vibration isolators, whose main operating element of one or several steel coil springs (cylindrical coil springs, cylindrical or conical);

- Rubber or rubber-metal vibration isolators whose main working body of the rubber complex forms;

- Vibration isolators are made of thin pressed steel parts (known as "metal rubber");

- In the form of an elastic material placed between the layers and foundations;

- In the form of a floor on an elastic basis which is commonly used in two-layer mode of vibration isolation.

Hammers are machines dynamic action, in which the kinetic energy of the moving mass is converted into work required for execution the process of deformation - forging (Fig. 2). According to the basic design characteristics hammers are divided into: hammers with anvil and without anvil, ie. anti-impact hammers.
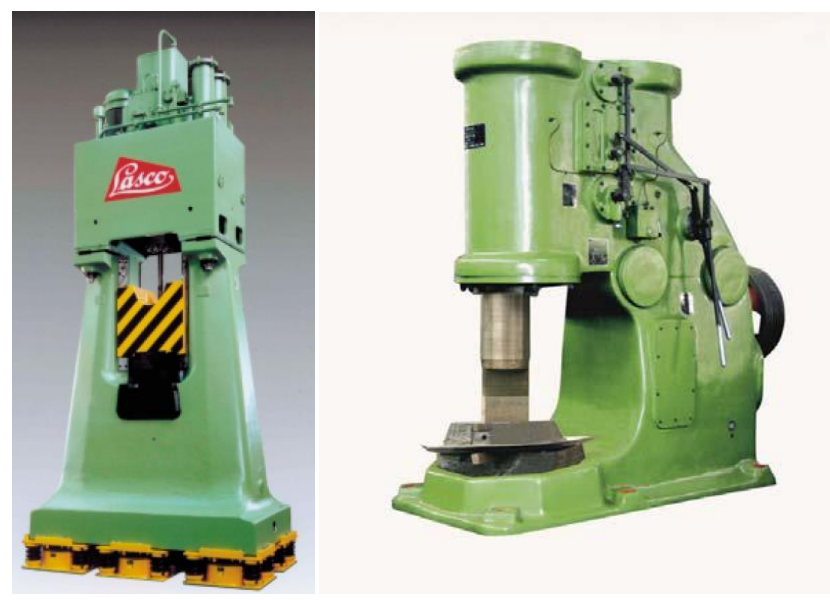

Fig. 2. Impact hammer and press forging-examples

Construction of heavy impact machines (impact hammers and forging machines) makes: the support structure, propulsion system, working part of the management system, lubrication system, auxiliary systems and security systems.

Hammers are selected on the basis of data obtained by designing technological process of forging. Basic specifications of hammers: nominal (available) energy, mass hair, no hair strokes per unit time, the maximum stroke of hair, forehead hair surface, the surface of the table, face the pressure of the working fluid, the working fluid consumption in a certain period of time, the weight of an anvil, dimensions the hammer and the total mass of the hammer. [2]

Starting the pneumatic hammer mallet is carried out with compressed air from the compressor which is a constituent part of the hammer. While the piston compressor down is done raising the pile, and to move the piston compressor up, accelerating the hammer down. Stroke rate of hair corresponds to the number of strokes of the piston compressor unit time.

Foundations hammer is the basis on which is placed a hammer and anvil. When operating the hammer foundation receives strong impact loads causing his movement and vibration. Since the foundation structure largely depends on the proper functioning of the hammer, as well as the noise level in operation.

Foundations can be a support suitable for reception of strong impact and dynamic loads. Impact is based on the share based rigid structures and vibroisolation based.

The support foundation - is a reinforced concrete block to which is attached a hammer. It is used in anti-shock hammer (hammer with movable anvil) where there is no strong shocks and vibrations. On the basis of the casted anchors for binding hammer. This method is based mainly used in areas where it is not hard court. [4]

Impact based applied for admission shock loads in all hammer with anvil. Impact foundation of reinforced concrete block certain mass and the supporting surface, which is determined by examining the technical documentation for the machine that is being prepared. 
Being built as a one-piece or multi-piece. If the drive there is more hammer is based can not be separated or connected in a linear configuration. Anvil hammer is placed on the rubber basis in order to mitigate impact load. The diagram (Fig. 3) shows vibration values of hammers with and without isolation system. Vibrations are reduced by more than $80 \%$ compared to rigid foundation. [5]

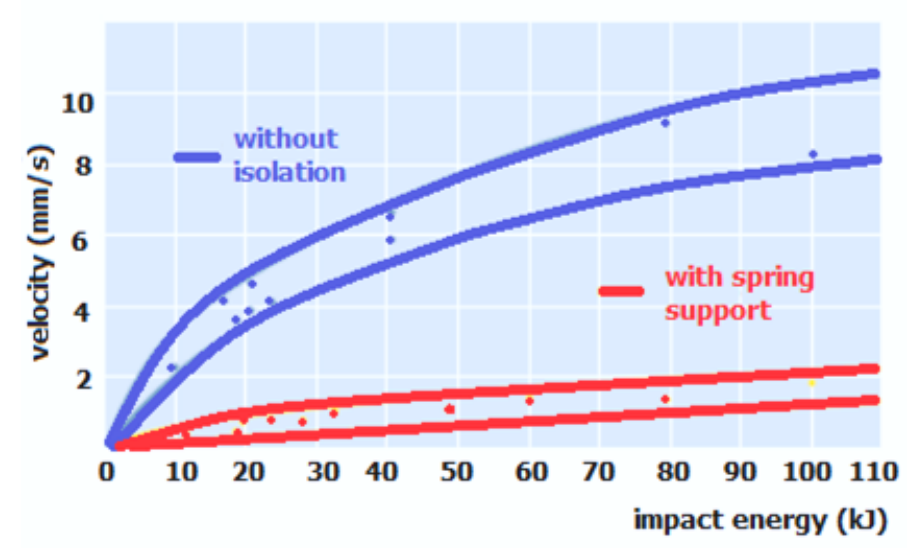

Fig. 3. Measured vibrations velocities of impact machine (in a distance of $10 \mathrm{~m}$ )

Vibration isolation of impact machines is a process which is very difficult to do well because of the large mass of the machine, and the enormous force of the blows produced by the machine.

\subsection{Characteristics of vibration isolators}

There are two types vibroisolators: isolators with series soil springs with viscous fluid dampers and elastomeric isolation systems.

Proper selection and optimization of structural parameters of these types of isolators leads to better characteristics vibration isolation impact machines.

Both types have proven to be very effective in isolating hammer and impact forces. Isolators with springs and viscous dampers provide better isolation characteristics, but they are quite expensive, require expensive foundations and tend to maintenance and repair. Viscous dampers in isolators with springs are difficult to protect, especially if you have a hole for the foundation prone to flooding, as in this case require the replacement of the fluid in the shock absorbers. [6] [8]

Some shock absorbers/dampers are designed to have cracks to leak into the walls of the foundation, which prevents their replacement in case of need and repair. For these reasons, these types of isolators are becoming the standard in the isolation of vibration and impacts (Fig. 4).

They offer the best isolating properties, with no major inertial mass, in case of flooding and no major maintenance costs related to the isolators with coil springs. They are very easy to install and maintain and are very long-lasting. This work seeks to contribute to solving the technical problems involved in the process of isolation of forging machines. When it comes to protective coating process, forging machine with impact hammer must be analyzed while: a bump in the lowering phase, while performing an action on an object and when it is in the stage of raising.

The ability of the impact machine is generally determined by the level of energy that can be obtained from the dropping weight and the upper parts of the machine.

Most impact machine is designed so that their weight starts to drop the initial zero and reaches a speed of 6-7 m/s when striking the workpiece. Some also hammers accelerating fall by a piston driven by steam, pneumatic or hydraulic pressure accumulator. It is important that the isolating system applies a sufficient amount of damping so that there is no movement when there is going to blow.

If the system is moving down when he gets the next blow, the blow will increase the amplitude of movement down more than the previous impact, which affects an overloaded system isolation and leads to instability of the whole structure. For softer installed isolating systems, when it comes to speeding up work hammer, the hammer can be loaded isolating system which leads to instability.

Usually, the hammers have enough weight so that their recoil is less of a problem than hitting the object. 


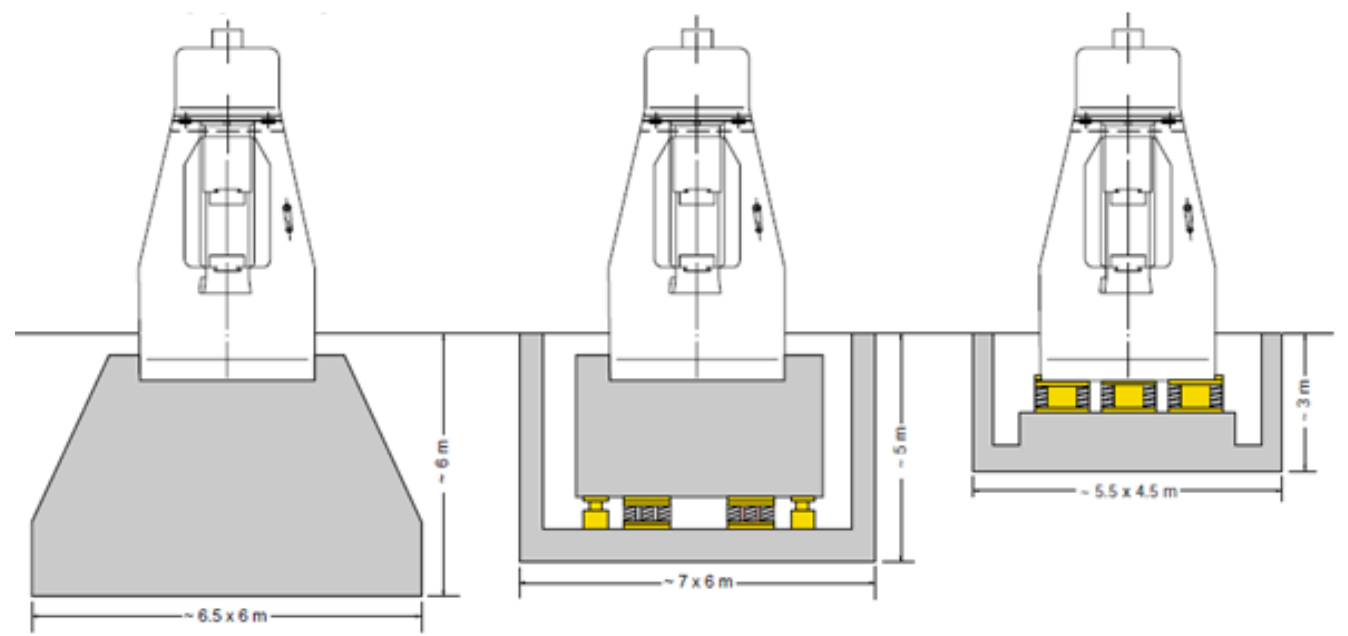

Fig. 4. Examples of vibroisolation foundations in section [5]

For a short time from when it happens contact with the workpiece and its deformation is the most important time in the working oparation of impact hammer. There is a wide range of forge work that can be done with a hammer, so that the magnitude of the induction force and duration of the force can vary significantly.

Increased heat workpiece allows a lower magnitude of the impact force and shortening the duration of the force on the workpiece. The final blows in forging blows the hardest. Analysis of the reaction anvil shot is actually simplified by the fact that many more massive anvil of tools for impact and that the impact takes a very short time. Tool for shock moving down while the speed of the anvil increases to equal the speed of the tool, and rebounds. Engineers have to understand that the cause maximum force on hammer, so that the anvil must be much more massive than him.

The theoretical force induced on the hammer relative to the extremely massive anvil is 100 times the hammer. It has been reported that up to 10 times the mass of the anvil increased very little changes attained the size of the force.

Vertical movement forgings depends on several parameters, the most important are the mass of the anvil and rigid systems, ie. changes in the system of hammers decreases when the mass anvil increases and movement increases with less rigid systems of lower natural frequency.

If applied generally accepted limit of several mm size of the movement, it is clear that the coil springs and elastic systems there is a need for such weight anvil which would maintain the natural frequency and characteristics of isolation performance, as shown in Figure 5. [5]

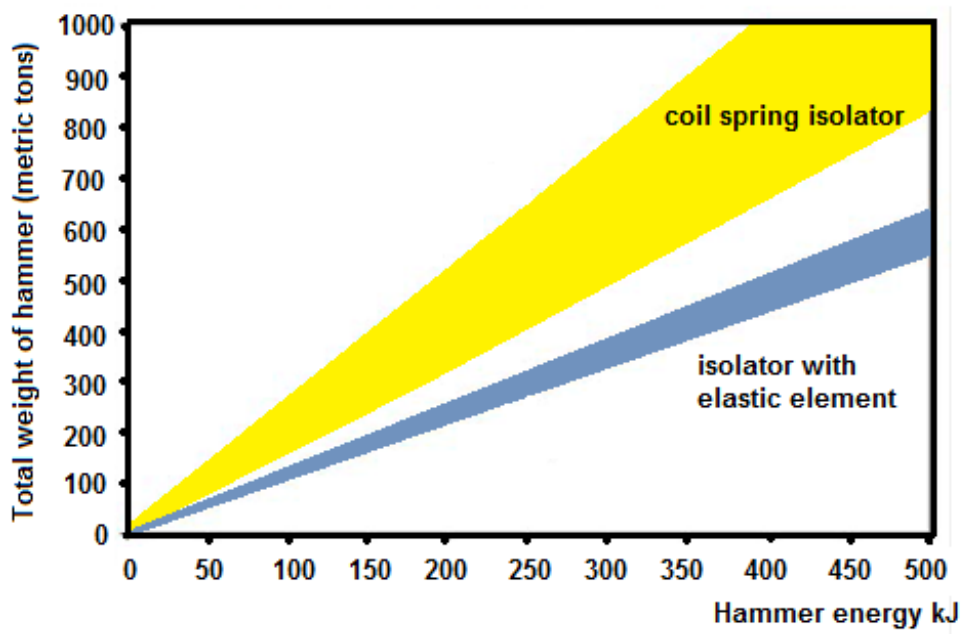

Fig. 5. Required hammer weight to achieve a $7 \mathrm{~mm}$ peak maximum response

Because the cost of adding concrete or steel inertial mass, isolator with elastic elements are more economical while keeping the same quality of isolation. Steel inertial mass are more economical, because the steel plate is denser and requires less space, thereby reducing the space and the size of the foundation. [7] 
Studies have shown that the steel inertial masses more durable the same load. The force transmitted to the foundation is the product of isolation system dynamic stiffness and movement of anvil.

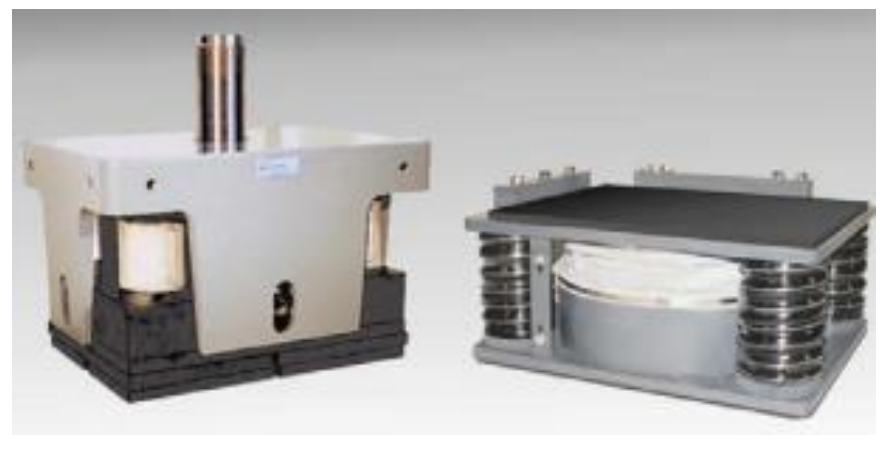

Fig.6. Isolator with elastic elements and steel coil spring type isolator [4]

For coil spring isolators, the addition mechanism with viscous damper adds a small amount of force to the force transmitted by support the springs. [9] For isolators with elastic element, the damping of the material is included in the real dynamic stiffness. The forces generated in the prime area of the enormous (Figure 6).

The exact size and duration of of the operation is usually not known, because measuring force is not possible. However, experienced workers on machines with impact hammers can be easily noted a significant reduction in fatigue of the components of the structure in relation to the traditional machines with impact hammers without isolators of this type. The correct application of optimal isolation system will result a significant reduction in the enormous influence of impact hammers.

Isolation systems with springs or elastic elements affect drastically reducing shock loads of high amplitude. Optimization of isolation of impact vibration to reduce health problems, reduce maintenance costs of the construction of the facility in which these machines are installed, reducing the formation of noise at work, and reduces the cost of the foundation. [5]

\section{Conclusion}

The main conclusion is that shown vibration isolators, ie. elastic systems with special configurations and proper selection of its parameters, have a decisive role in increasing the degree of isolation of the base structure.Vibration isolation of impact machines require a special consideration because they transmit dynamic loads to soil in addition to static loads due to weight of foundation, machine and accessories. The dynamic load due to operation of the machines is generally small compared to the static weight of machines and the supporting foundation.

The paper presents results of research on the impact machinery proving optimal design vibration isolators with coil springs and elastic elements in relation to the vibrational isolators with inertial masses. Studies have shown significant differences in the amount of vibrational amplitude of the transmitted dynamic force of impact. For greater impact energy that is transmitted to the vibration isolator with coil springs and elastic elements, the speed of vibration is reduced by up to ten times.

On the basis of impact machines occurs dynamic load during a long period of time, but its small size. Therefore perform optimization vibration insulation foundations to allow better flexibility because, otherwise, the deformation becoming greater with each load cycle which can become quite unacceptable.

Isolation systems with coil springs or elastic elements have proven to be very effective in isolation shock vibration on machines with impact hammers. Compared with traditional machines with striking hammer and their installation methods, such as wood and rubber flooring, isolation systems with coil springs and elastic elements are superior for faster and easier installation and assembly of the separate building. [10]

The amplitude of the vibration of the impact machine with its operating frequency, the coefficient of stiffness and damping vibration isolators are most important parameters that define in optimizing vibration isolation, with the nature frequency of the foundation structure of the machine. The two systems of isolation are cost effective and extremely durable.

In the last decade, research in this area have developed very good technology for the isolation of the impact of vibration on machines with impact hammers. But, recommendations for future research would be to prove even better quality combined vibration isolators. This is evidenced by the chart shows the relationship of the total weight of the impact of the machine (hammer) vs. the energy hammer that is transmitted to one or another type of isolators. 


\section{References}

[1] http://antivibration-systems.com/wp-content/uploads/2013/03/Catalog

[2] http://www.vibrodynamics.com/english/hammers.html Vibration and Shock Isolation Systems for Forging Machinery, Vibro/dynamics, Technical bulletin M/L- 697

[3] Schmidt, J. H.; Granchi, M.; Barth, T.M.: Optimal Vibration Isolation for Shock-Sensitive Machines, Bilz Vibration tehnology, Leonberg, Germany

[4] Chowdhury, I.: Dasgupta, S. P. (2009). Dynamics of Structure and Foundation, Taylor\&Francis Group

[5] https://www.gerb.com

[6] Fulan, P. (1988). Theory and Experiment of Hammer Foundation Vibration, Proceedings: Second International Conference on Case Histories in Geotechnical Engineering, St. Louis, Mo., Paper No. 4.05

[7] Prakash, S.; Puri, V. K. (2006). Foundations for Vibrating Machines, Special Issue, of the Journal of Structural Engineering, SERC, Madras, India.

[8] Broch, J. T. (1984). Mechanical Vibration and Shock Measurements, Brüel \& Kjær, ISBN 8787355345

[9] Dragičević, M.; Šaravanja, D. (2012). Vibration Analysis Within Dynamic Testing of the Diesel Generator HE Mostarsko Blato, Zbornik radova Fakulteta strojarstva i računarstva Sveučilišta u Mostaru, ISSN 1986-5236, Mostar

[10] Leopa, A; Nastac, S.; Debeleac, C. (2012). Researches on damage identification in passive vibro-isolation devices, Shock and Vibration 19, 803-809, DOI 10.3233/SAV-2012-0689 IOS Press 